\title{
Article \\ Selection of Smart Grids Projects of Common Interest-Past Experiences and Future Perspectives
}

\author{
Julija Vasiljevska and Tilemahos Efthimiadis *(D) \\ Energy Security, Distribution and Markets European Commission-Joint Research Centre (JRC), \\ 1755 LE Petten, The Netherlands; julijavasiljevska@gmail.com \\ * Correspondence: tilemahos.efthimiadis@ec.europa.eu; Tel.: +31-224-565-003
}

check for updates

Citation: Vasiljevska, J.; Efthimiadis, T. Selection of Smart Grids Projects of Common Interest-Past Experiences and Future Perspectives. Energies 2022, 15, 1915. https://doi.org/ $10.3390 /$ en15051915

Academic Editors: Adalgisa Sinicropi and Abu-Siada Ahmed

Received: 21 January 2022

Accepted: 2 March 2022

Published: 6 March 2022

Publisher's Note: MDPI stays neutral with regard to jurisdictional claims in published maps and institutional affiliations.

Copyright: () 2022 by the authors. Licensee MDPI, Basel, Switzerland. This article is an open access article distributed under the terms and conditions of the Creative Commons Attribution (CC BY) license (https:// creativecommons.org/licenses/by/ $4.0 /)$.

\begin{abstract}
This paper discusses the authors' experience gained with the selection of Projects of Common Interest (PCIs) in the thematic area of smart grids deployment, in the context of the TEN-E Regulation. It presents the framework for assessing candidate electricity smart grids for inclusion in the European Union list of PCIs, in view of the TEN-E Regulation and the existing literature on assessment methodologies for energy infrastructure projects. It also provides an overview of smart grid projects included in the PCI lists, with the aim to shed light on the types of projects and their contribution to accelerating the development of European cross-border energy infrastructure projects to respond to EU energy and climate targets. The paper concludes with discussion of recent regulatory initiatives and their potential implications on the presented methodology.
\end{abstract}

Keywords: electricity; smart grids; cost-benefit analysis; investment; regulation

\section{Introduction}

The European Union (EU) strives to become the 'first climate-neutral continent, through the implementation of the European Green Deal' [1]. This transition to a climateneutral society will require significant investments in the energy sector, especially for infrastructures. One of the many EU policies for supporting such investments is the Trans-European Networks for Energy (TEN-E), which focuses on linking the energy infrastructures of EU countries and is codified in Regulation (EU) No 347/2013 (hereinafter 'the Regulation') [2].

The implementation of the TEN-E policy is mainly conducted through the adoption of the list of Projects of Common Interest (PCIs), which consists of energy infrastructure projects with cross-border impacts aiming to increase sustainability, security of energy supply and market integration. The first PCI list was adopted in 2013 [3] and a new one is drafted every two years.

The PCI status provides numerous benefits to infrastructure projects including an accelerated permit granting process, improved regulatory treatment, eligibility for EU financial support through the Connecting Europe Facility (CEF) [4], increased visibility to investors, etc.

Electricity smart grids is one of the PCI infrastructure categories. While only two such projects were included in the first list, five were included in the fifth and most recent list published in 2021 [5].

In this paper, we discuss our experience gained with the selection of PCI in the thematic area of smart grid deployment, and provide recommendations on how the assessment framework for projects selection can be more aligned with the new TEN-E objectives, for example, providing support to the European Green Deal.

Electricity smart grids (hereafter 'smart grids') may facilitate the integration of renewable energy source (RES) and distributed generation into the electricity grids and enable demand-side management. They can also help in reducing outages and the need for new 
electricity transmission lines and increase system efficiency. Therefore, smart grids can assist in increasing the sustainability, efficiency, and digitalisation of the energy sector.

According to the Regulation, a smart grid project can receive the PCI label if it:

1. is necessary for at least one energy infrastructure priority area or corridor (listed in [2]),

2. demonstrates cross-border impacts by crossing the border (e.g., electricity transmission line) of at least two Member States, or one Member State and a European Economic Area country, or is on the territory of a Member State and has a significant cross-border impacts (Annex IV.1 of the Regulation),

3. demonstrates that the potential overall benefits of the project outweigh its costs, including in the longer term. The Regulation provides the criteria against which the benefits are assessed.

In the context of the second requirement above, a smart grid PCI does not necessarily need to involve a physical interconnection between countries. Instead, it could concern a digital infrastructure that enables increased network data exchange, therefore demonstrating a cross-border impact through, for example, a better exploitation of existing interconnection capacity and more cost-efficient solution to usual challenges in the crossborder area. An example of such a project is SINCRO.GRID [6], included in the second (2015), third (2017) and fourth (2019) PCI lists. The project regards establishing a virtual cross-border control centre to facilitate the integration of renewable energy in Slovenia and Croatia. Another example is the Danube InGrid [7], which focuses on smartening data collection and data exchange for enhancing cross-border coordination of electricity network management.

The rest of the paper is organised as follows: In Section 2, we first provide the requirements of an assessment methodology for candidate smart grid PCIs, also in view of the TEN-E Regulation, and briefly discuss alternative approaches in the literature. We also provide an overview of the assessment framework used for smart grid PCIs (developed by the Joint Research Centre, JRC), including main challenges identified in its application since the adoption of the first PCI list in 2013. In Section 3, we describe the smart grids PCIs which were included in the PCI lists, along with their challenges, goals, and impacts. In Section 4 we present recent policy and regulatory developments which should lead to an updated assessment framework. We end the paper with an overview of our recommendations based on the first-hand experience we had in developing and implementing the framework, along with our support to project promoters for preparing their proposals. Section 5 summarises the paper.

\section{The Assessment Framework}

\subsection{Overview of Requirements}

In the Regulation a smart grid is defined as 'a network efficiently integrating the behaviour and actions of all users connected to it-generators, consumers and those that do both-in order to ensure an economically efficient, sustainable electricity system with low losses and high quality and security of supply and safety' (Article 2(7)). The Regulation also specifies a smart grid infrastructure as 'any equipment or installation, both at transmission and medium voltage distribution level, aiming at two-way digital communication, real-time or close to real-time, interactive and intelligent monitoring and management of electricity generation, transmission, distribution and consumption within an electricity network (Annex II (1)(e)).

The main high-level requirements for a candidate smart grid PCI are the following: (1) the project is necessary for the smart grid infrastructure priority area, as defined in the Regulation and mentioned above; (2) it has positive cross-border impacts; and (3) the potential overall benefits assessed according to the specific criteria outlined in the Regulation outweigh its costs (Article 4 (2) (c)).

The specific policy criteria are the following: (1) integration and involvement of network users with new technical requirements regarding their electricity supply and 
demand; (2) efficiency and interoperability of electricity transmission and distribution in day-to-day network operation; (3) network security, system control and quality of supply; (4) optimised planning of future cost-efficient network investments; (5) market functioning and customer services; and (6) involvement of users in management of their energy usage.

Furthermore, it is important to note that candidate projects are not ranked unless they concern the same two Member States. In those cases, the ranking is done considering the number of users affected by each project, the annual energy consumption, and the share of generation from non-dispatchable resources in the area covered by these users.

\subsection{Development of an Assessment Framework}

The assessment framework (hereinafter 'the framework'), described in detail in [8] and outlined in the following section, aims to facilitate the selection of smart grids projects to be included in the PCI lists, that is, to provide an independent evaluation of the candidate projects to the TEN-E smart grids Thematic Group which includes Member States, the European Commission, the European Network Transmission System Operators for Electricity (ENTSO-E, Brussels, Belgium), national regulatory authorities, Transmission System Operators (TSOs), NGOs, etc.

The goal of the framework is to assess all candidate projects in a homogenous way, displaying their costs and societal benefits at the European level. Based on this assessment, the decision-making body of the smart grid Thematic Group adopts the list of smart grid projects, as part of the Union list of Projects of Common Interest [2].

In general, a framework for evaluating energy infrastructure proposals for receiving public support needs to consider several principles, such as a project's relevance for the underlying policy goals, the need for support, its desirability from a socio-economic perspective, etc. [9]. For this, an analytical tool that is often applied is the social cost-benefit analysis (CBA), where both costs and societal benefits are valued in monetary terms, externalities considered, etc. $[9,10]$ A meticulously designed social CBA also helps reduce potential policy biases and can increase accountability while facilitating consistency in decision making, distinguish it from other decision methods such as majority voting, collective bargaining, etc. [11,12]. A discussion of social CBAs, and examples of its application for energy infrastructure projects, are provided in [13].

The appraisals usually rely on assessing the potential project's impacts regarding the policy goals, by comparing two scenarios, 'with' and 'without' the project $[14,15]$. However, such approaches are often criticised as inadequate when considering uncertainties over the lifetime of each project (for example, [15]).

In 2009, the EU adopted the Third Energy Package [16], which put forward smart meters-a building block for the digitalisation of the electricity grid-as enabling technologies for more efficient and sustainable use of energy. In 2012, the JRC developed a CBA for smart metering projects [17] to support Member States in implementing the Third Energy Package provisions on smart metering deployment, followed by a CBA of smart grid projects $[18,19]$. This methodology was the basis for the selection process of smart grids PCI in 2013 and 2015, before being updated in 2017.

A few applications of the CBA for smart grid projects followed, in 2015, for the city of Rome [20] and in 2018 for the INSERNIA project [21]. In general, a framework must be fit-for-purpose, that is, it must account for the specificities and peculiarities of the policy goals, project promoters' constraints, available tools, and time for drafting proposals, etc. In the context of the smart grids PCIs, a framework needs to fulfil several requirements, including full compliance with the Regulation; transparency; a straightforward application; approval by the relevant TEN-E Thematic Group; and that the data, calculations and other information required from candidate project promoters is feasible and not overbearing. The last point is of importance given that:

- Many project promoters (will) have limited funds or in-depth modelling experience, especially given the small scale of most of the candidate projects. Furthermore, smart grids proposals tend to not be very mature, at least in comparison with other PCI 
infrastructure categories (e.g., electricity transmission). Characteristically, no smart grid PCI was completed by end-2021.

- The time allocated for preparing PCI candidate project submissions is often short.

- The number of candidate PCIs so far has been small (compared to other PCI categories, e.g., electricity transmission). Nevertheless, given the recent policy developments and the ongoing revision of the Regulation, we expect an increasing number of candidates in the next PCI calls.

- Candidate projects do not need to be ranked unless they concern the same Member States [2]. Thus, rigid, common benchmarks are not always necessary.

In addition to the requirements, developing such a framework has further challenges given that:

- Most candidate projects are too small to be included into a system-wide analysis to estimate their impacts. For example, they are not included in the Ten-Year Network Development Plans [22] published every two years by ENTSO-E.

- The project proposals are dissimilar in their scope, for example, they have diverse types of infrastructure assets.

- There is an eligibility requirement concerning the cooperation between distribution system operators (DSOs) and TSOs, which is not always given.

- A standardised monetisation is not straightforward for some specific criteria of the Regulation, given some benefits can be quite diverse and not easily quantifiable, e.g., involvement of users in management of their energy use, improvements in market functioning, etc. For example, given the expected benefits and avoided costs of smart grids, one would expect that the value of lost load (VOLL) to be central to the assessments. However, only in 2020 were Member States obliged to calculate and make publicly available a single estimate for VOLL on their territory (Article 11 of Regulation (EU) 2019/943). Furthermore, the Agency for the Cooperation of Energy Regulators (ACER) published a methodology for calculating VOLL only in October 2020 [23]. In this context, there is a need for (also) assessing benefits through non-monetary metrics.

Given the principles of an assessment framework and the above requirements and based on the current challenges European network operators face, we discuss opportunities in Section 4 about how an adjusted assessment framework could facilitate and accelerate development of smart grids projects in the context of the TEN-E Regulation and in view of its objective to support the European Green Deal.

\subsection{The PCI Smart Grid Assessment Framework}

Considering the above requirements and challenges, the European Commission (EC), in particular the Joint Research Centre, which is EC's in-house science and knowledge service, developed, updates and implements the framework that supports the selection of smart grids PCIs. The framework has been used continuously for the PCI selection process since the drafting of the first PCI list in 2013 and is presented in detail in [8]. This subsection provides an overview of the main steps of the framework and the tools used for implementing each step. As not all costs and benefits can be monetised, the framework employs a multi-criteria approach, aiming to utilise divergent information and to provide the decision makers with a coherent analysis. To streamline this analysis, the framework requires that each candidate smart grid PCI be evaluated through a series of steps as follows (we present the step and the tool for implementation):

1. Compliance with eligibility requirements: Checklist.

2. Impact of the project: Key performance indicators (KPIs).

3. The project's economic viability: Social cost-benefit analysis (CBA) to determine if the overall benefits outweigh costs.

4. Evaluation of further impacts (if applicable): Ad-hoc based-on information provided by the project promoter on impacts that are not captured by the CBA or KPIs. 
In what follows, we present an overview of each step of the framework.

\subsubsection{Compliance with Eligibility Requirements}

The framework defines a relevant checklist for project promoters to fill-in for verifying the project's necessity for the smart grid infrastructure priority area, and its compliance with the TEN-E general criteria (see [8]).

\subsubsection{Impact of the Project}

To obtain consistent and comparable quantitative analyses, the framework interprets the six specific criteria of the Regulation (also mentioned in Section 2 above) through a list of key performance indicators (KPIs) and provides guidelines on how they should be calculated by the project promoters.

For example, $\mathrm{KPI}_{6}$ refers to 'Methods adopted to calculate charges and tariffs, as well as their structure, for generators, consumers and those that do both'. In this case, the KPI is expressed qualitatively and includes the added information that could be measured with the project deployment and how this information can be used to define more accurate methods of allocating costs [8]. The full list of KPIs is provided in Appendix A.

The impacts are assessed as a comparison 'with' and 'without' the project, the former referring to the case where the project is thought to be in place in the system, and the later where the project is considered not have been deployed. While more complex approaches are available in the literature (e.g., [15]), the adopted approach has been characterised as adequate (e.g., see [24]) given the small number of candidate projects (so far), that some would have small impacts on the system, and that they do not overlap or compete. In other PCI categories, e.g., electricity transmission lines, Take-Out-One-at-a-Time and the Put-In-one-at-a-Time methodologies are employed [25].

\subsubsection{The Project's Economic Viability}

If the eligibility requirements are fulfilled, then (some of) the KPIs are used to assess the project's economic viability. For this, a social CBA is conducted where benefits and costs are monetised (some previously calculated in various KPIs), and economic indicators calculated, e.g., benefit/cost ratio,, economic internal rate of return and economic net present value. The calculations are performed by the project promoters and are provided for each individual year of the project's time horizon.

Given the diverse infrastructure assets, time horizons and geographical regions, project promoters can freely choose the underlying assumptions and parameters (demand growth, discount rate, etc.). However, they must also justify their choices, e.g., especially if the discount rate significantly differs from that assumed by the EC or the Member State. Furthermore, project promoters must provide a basic sensitivity analysis.

\subsubsection{Evaluation of Further Impacts}

The project promoter can provide information on impacts (positive and negative) that are not captured by the TEN-E specific criteria (KPIs) or the social CBA. Examples include impacts on societal acceptance, improvements in the performance of ICT systems, etc.

\section{Overview of Smart Grid Projects of Common Interest}

\subsection{Overview}

This section provides an overview of all smart grid projects included in the PCI lists, with the aim of exploring the type of projects and understand their challenges, goals, and impacts. Furthermore, the summary of each project below highlights the added value of pursuing a joint project, based on common challenges that both DSOs and TSOs face with ever-growing requests for RES connections, and in view of the electrification of other end-use sectors (heat and transport). 
All projects presented in this section were evaluated according to the assessment framework outlined above and described in detail in [8]. In a nutshell, each project was evaluated against the following information provided by the project promoters:

- Demonstration of a necessity for the smart grid priority thematic area (Annex II(1)(e) of the Regulation).

- Demonstration of a cross-border impact/relevance (Article 4 (1) (c) of the Regulation)

- Demonstration of a project's contribution to the six specific policy criteria of Article 4 (2) (c) of the Regulation. This entails a demonstration of a positive social cost-benefit analysis, where the potential overall benefits of the project are assessed according to the respective specific criteria in paragraph 2 (c), Article 4 of the Regulation and using the key performance indicators outlined in Annex IV (4) to the Regulation.

The comprehensive evaluation of each project proposal can be found in [26-30].

Figure 1 presents the smart grid PCIs included in the relevant lists while an overview of projects follows. The information presented was provided by the project promoters in their project submissions.

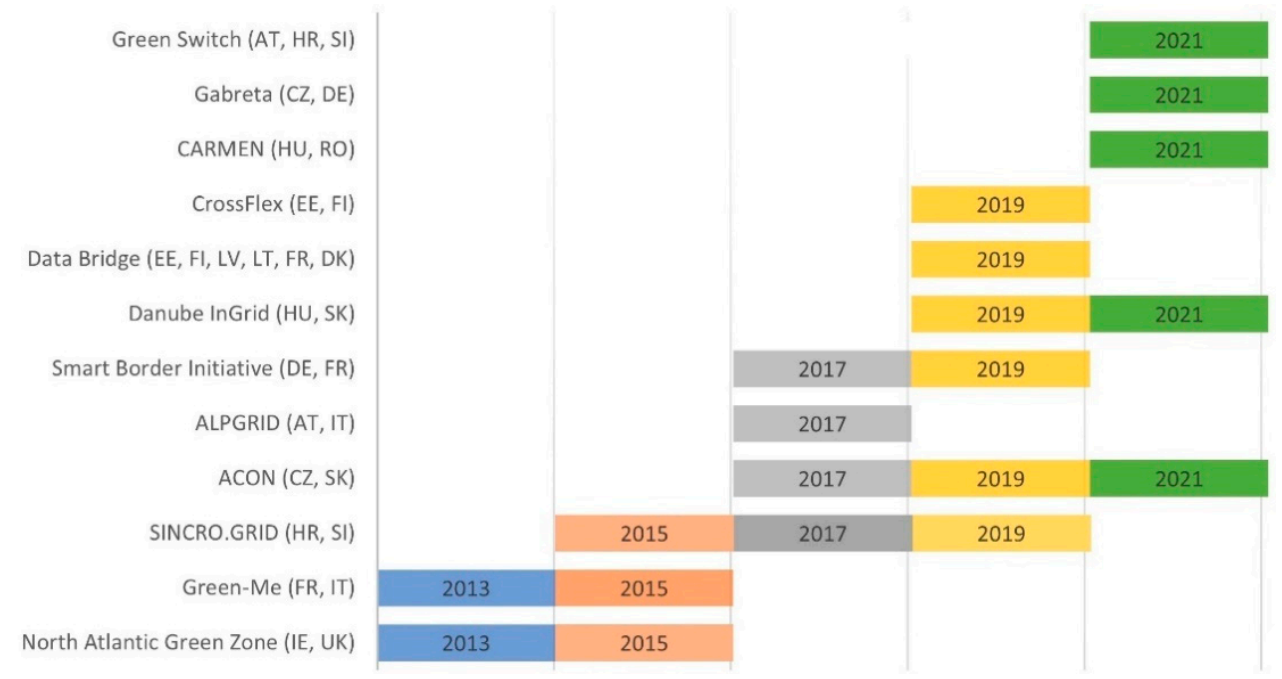

Figure 1. Smart grid projects of common interest in the PCI list between 2013-2021.

\subsection{Cross-Border Impact and Added Value of Each (Joint) Project}

The North Atlantic Green Zone project proposal [26,27] involved two DSOs and TSOs from neighbouring countries (Republic of Ireland and UK), and the project was included in the first and second PCI lists in 2013 and 2015, respectively (Figure 1). The project's main goal was to increase the distribution network hosting capacity for RES and improve the grid reliability in terms of reduction of outage times, by better controlling and monitoring the medium voltage distribution network. The project proposal demonstrated cross-border impact at both distribution and transmission network level, as the project focused on the development of communication and control software between the two $110 \mathrm{kV}$ interconnectors in the region to increase their exploitation rate through automated coordination in addition to smart grid investments at the distribution networks.

The Green-ME project proposal $[26,27]$ brought together DSOs and TSOs from two neighbouring Member States (France and Italy) with the aim to better manage the distribution and transmission networks and increase the maximum hosting capacity of both networks in the region in light of increasing requests for RES connections. It was included in the first and second PCI lists (Figure 1). The major smart grid solutions included increased monitoring, controllability and predictability of distributed RES while maintaining the reliability and security of the network, and in particular avoiding curtailments of net transfer capacity (NTC) between the two Member States in case of over-generation from RES combined with low-load conditions. The project proposal demonstrated cross-border 
impact at transmission network level as the project also aimed to increase the exploitation rate of the interconnector between the two Member States and limit NTC reduction due to enhanced controllability and observability of distributed RES, connected mainly at the distribution network in the project area.

The SINCRO.GRID project promoters benefit from a common approach to existing network challenges in the region linked to voltage control resulting from increased penetration of RES, in addition to the high degree of transit power flows in the project area. The project proposal $[27,28]$ included the whole geographic areas of Slovenia and Croatia, and the project was included in the second, third and fourth PCI lists (Figure 1). The project started in November 2016 and its first phase is foreseen to end in March 2022. The added value of carrying out a joint project resulted in deployment of a common virtual cross-border control centre, thus leading to reduced need for voltage compensation devices, which would otherwise be necessary to be installed on both sides of the border to effectively deal with high network voltages. The project involves TSOs and DSOs from both neighbouring Member States and it demonstrates cross-border impact at transmission network level, with significant investments also taking place at the distribution network.

The ACON project's goal is to effectively respond to future distribution network challenges in the project area related to stability and reliability issues in the presence of a growing level of RES. To this end, the project proposal [28-30] involved DSOs from two neighbouring Member States to carry out smart grid investments on existing cross-border distribution network lines and installation of additional $110 \mathrm{kV}$ and $22 \mathrm{kV}$ interconnectors. It was included in the third, fourth and fifth PCI lists (Figure 1). Some of the smart grid investments concerned cross-border bidirectional digital communication to enable interactive and intelligent monitoring and management of the electricity network through better involvement of network users in management of their energy usage. In this regard, the project demonstrated cross-border impact at distribution network level. Furthermore, the countries' TSOs are expected to benefit from more efficient and reliable operation of the distribution networks in the project area.

The ALPGRID project proposal [28] brought together promoters from two neighbouring countries (Austria and Italy) and the project was part of the third PCI list in 2017. It built on deployment of mature technologies for distribution networks monitoring and control and develops an innovative cross-border flexibility platform where market players (flexibility providers, aggregators, etc.) can provide flexibility to both DSOs and TSOs in the region. In this sense, it involved three DSOs and aggregators and energy storage operators from Austria and Italy. The development of the project's cross-border flexibility platform can facilitate the provision of flexibility solutions to the electricity systems and this way allow integration of growing levels of RES. The project demonstrated cross-border impact at transmission network level in terms of increased NTC and participation of network users in electricity markets across the border.

The Smart Border Initiative project proposal $[28,29]$ was driven by existing challenges in the region, and it responded to those challenges by offering an integrated approach of a cross-border distribution network optimisation, smart mobility solutions and sector coupling, with the aim to improve energy efficiency, security of supply and network resilience in the project area. It was part of the third and fourth PCI lists (Figure 1) and the project involved DSOs and TSOs from Germany and France and other market players (e.g., technology manufacturers). The project proposal demonstrated cross-border impact at distribution network level by development of optimised cross-border electricity distribution systems to be integrated in the market and grid operation of both Member States, which is expected to result in improved balancing of local generation and consumption at the DSO level and increased integration and use of flexible resources (electric vehicles, demand response, etc.).

The CrossFlex project [29] was Ided in the fourth PCI list (Figure 1). It aimed to support RES integration and increase security of supply in mainland Finland, its Åland Islands and Estonia by development of a necessary infrastructure for cross-border provision of 
flexibility services provided by distributed generation connected to both distribution and transmission networks. In this sense, the project proposal addressed system needs for increased flexibility in the project area by using and coordinating existing infrastructure, i.e., high-voltage direct current (HVDC) systems and distributed generation. The project proposal involved TSOs from two Member States (Finland and Estonia), as well as DSOs and investors of flexibility resources. The proposal demonstrated cross-border impact at transmission network level as it aimed to further increase the utilisation of the HVDC interconnectors in the project area and consequently widen and strengthen the portfolio of flexibility services.

The Danube InGrid project $[29,30]$ was included in the fourth and in the most recent (fifth) PCI list (Figure 1). The proposal aimed at enhancing cross-border coordination of electricity network management, with a specific focus on smartening data collection and exchange to effectively respond to future needs and challenges in the region linked to integration of growing penetration levels of RES and electro-mobility, more cost-efficient operation of the electricity system and improved system reliability. It primarily leveraged existing physical interconnection at the distribution high-voltage level and focused on enlargement and smartening of networks' substation infrastructure and installation of remote control, data collection and exchange, and fault detection instruments. The proposal involved DSOs and TSOs from Hungary and the Slovak Republic and it demonstrated cross-border impact at distribution network level, which is also expected to foster increased exploitation of the transmission network interconnections in the project area.

The Data Bridge project [29] was part of the fourth PCI list (Figure 1). The proposal made a direct reference to Article 23 of the Directive (EU) 2019/944 on common rules for the internal market for electricity [31] in which EU Member States are required to ensure access and share of energy data of consumers upon their consent. Its main objective was to ensure interoperability across different data hubs by developing a common European data nridge platform allowing DSOs and TSOs to process and manage smart metering data. This will also allow energy suppliers, aggregators and other service providers to access data from a single application programming interface and offer their flexibility to the TSOs and DSOs across Europe. The project involved five TSOs and three DSOs from six EU countries (Denmark, Estonia, Finland, France, Latvia and Lithuania) with the goal of eventually covering all EU Member States. The proposal demonstrated potential for cross-border impact at both transmission and distribution network level as it aimed to increase data sharing across borders to response to different flexibility needs of the operators (DSOs and TSOs), which can result in better exploitation of interconnection capacities in the project area.

The CARMEN project [30] is included in the most recent (fifth) PCI list. Its proposal builds on the principal need to improve the quality of service and efficiency of the electricity distribution network in one of the Member States (Romania) involved in the project in view of growing requests for connection of RES on the east side of Romania, which can ultimately result in increased power flows from the east to the west of the country. Such increase of power flows can impact the transmission grid as well, and necessitate increased cooperation with the TSOs. Additionally, the project is expected to enable growing requests for RES connection on the transmission network in Romania and allow secure and efficient flow of this renewable energy across border, thus also impacting the transmission grid of the other Member State (Hungary). The proposal brought together one DSO and two TSOs from two neighbouring countries which would benefit from more intense cooperation primarily in the field of data exchange and know-how, expected to facilitate the management of emergency situations associated with increased deployment of variable RES in the future.

The Gabreta project [30] is included in the most recent (fifth) PCI list. The proposal aimed to better integrate the electricity distribution networks of two neighbouring countries (Czech Republic and Germany) by increased exchange of data and energy, and by close coordination of the management of frequency, voltage, and reactive power in presence of growing penetration levels of RES. Some of the smart grid upgrades included infrastruc- 
ture strengthening the interaction of distribution grids through digitalisation of secondary substations, remote monitoring, metering and control infrastructure and implementation of data hubs and cross-border data sharing platforms. Therefore, the proposal demonstrated cross-border impact mainly at a distribution network level. It involved DSOs and TSOs from two neighbouring Member States and some of the direct impacts of a joint project include improved security of supply, resilience, flexibility of the distribution and transmission network as well as increased ability to safely integrate high penetration levels of distributed RES.

The Green Switch [30] project is included in the most recent (fifth) PCI list. The proposal is developed on the need to effectively address growing requests for RES connections and increased peak load, also owing to integration of electric vehicles and heat pumps, which has recently resulted in increasing power flows in both distribution and transmission grids. To be able to respond to these challenges in a more cost-efficient way, the DSOs and TSOs involved in the project have recognised the need for stronger cooperation and coordination. The project's solutions also build on the value of sector integration in the field of mobility and heating and consequently increase system flexibility and efficiency. The project proposal involved TSOs from two (Slovenia and Croatia) and DSOs from three neighbouring countries (Slovenia, Croatia, and Austria), retailers, and a power producer. The proposal demonstrated a cross-border dimension both at transmission and distribution network level as it aimed to increase the capacity of existing cross-border transmission interconnectors, as well as to increase the cross-border capacity at the DSO level.

Out of these twelve smart grid projects included in the PCI lists, eight are led by DSOs. In other words, the majority of the investments occur at the distribution network level. Nevertheless, in all these projects, TSO-DSO cooperation is a central building block in addressing the project needs. Furthermore, recent project proposals (e.g., CrossFlex, Data Bridge, SBI) include aspects such as cross-border flexibility provision and sector-coupling to respond to ever-growing challenges linked to integration of renewables and electrification of other end-use sectors, such as heating and transport. Other projects, such as Green Switch and Danube Ingrid build their project proposals on existing successful experiences of the project promoters in previous smart grid PCI (SINCRO.GRID [6] and ACON [32], respectively).

As for the implementation, only two projects (SINCRO.GRID [6] and ACON [32]) are under construction and one project (Danube InGrid [7]) is in its permitting phase. Except the new projects included in the last PCI list (CARMEN [33], Gabreta [34] and Green Switch), the rest of the projects have faced various challenges, linked to permitting procedures, national regulatory treatment or did not manage to receive EU financial support $[35,36]$. Furthermore, the promoters claim that permit-granting procedures, as set out in the TEN-E, need to be effective for distribution network projects as well and the TEN-E Regulation needs to be fully applied across all Member States to avoid delays in permitting procedures [37].

\section{Policy and Regulatory Developments}

A set of policy developments took place since the adoption of the first PCI list in 2013. A major initiative is the European Green Deal [1], adopted in 2019, as it has a strong emphasis on sustainability and highlighting the increased need for smart infrastructure including electricity and gas smart grids, to accelerate the scale-up of RES generation and facilitate rapid electrification of other end-use sectors, while ensuring that Europe grasps the potential of digital technologies to provide solutions to societal challenges [38]. Another example is the revision of the Electricity Market Directive [31], which calls for a more active role for DSOs by allowing them to be both buyers of distributed flexibility, and facilitate others' use of flexibility resources in their own network to increase system-wide benefits. In this context, Article 23 of the Electricity Market Directive stresses the role of effective, secure, and easy access of final consumers' data to any eligible party in enabling demand response and other flexibility services. The EU Strategy for Energy System Integration [39] calls for 
greater synergies between energy and transport in the revision of both Regulation for the Trans-European Transport network and the TEN-E Regulation in view of energy network related support for cross border high-capacity recharging. It also highlights that 'better integration will provide additional flexibility for the overall management of the energy system and thus help to integrate increased shares of variable renewable energy production. 'Furthermore, the EU strategy for smart system integration stresses the importance of development of a Network Code on Demand Side Flexibility (under Regulation (EU) 2019/943) to 'unlock the potential of electric vehicles, heat pumps and other electricity consumption to contribute to the flexibility of the energy system'.

To conclude, the EU strategy for system integration highlights the importance of smart grid infrastructure in accelerating the electrification of new end-users, which in addition to significant grid reinforcements at the distribution level (and secondly at the transmission level), also calls for more efficient use of existing electricity grid-enabled by smart grid infrastructure.

Furthermore, the European Parliament also called for a revision of the TEN-E guidelines for aligning 'the legislative framework with the priority of smart grid deployment and to prevent the lock-in of carbon-intensive investments' [40] to contribute to climate and energy targets as part of the most recent EC's legislative package "Fit for 55" [41]. The later aims for a reduction of 55\% of greenhouse gas emissions by 2030 compared to 1990. This requires massive investments in infrastructure, especially in energy, transport, and urban infrastructure.

In December 2020, the Commission adopted a proposal (COM(2020) 824 final) to revise the EU rules on the TEN-E Regulation, in view of the European Green Deal [42] and the Commission communication 'A Clean Planet for all-a European strategic long-term vision for a prosperous, modern, competitive and climate neutral economy' [43].

Electricity smart grids are crucial for achieving the objectives of the above initiatives as they can facilitate the integration of demand-side management and distributed and RES generation, thereby also reducing the need for new electric transmission lines. Smart grid investments also contribute towards a more efficient use of existing network assets. To this end, regulatory frameworks in Europe play a pivotal role in properly incentivising smart grid investments [44]. Furthermore, through digitalisation of the power grid, outages can be potentially reduced while system efficiency can be increased [45]. We see in the previous section that a majority of the investments in the projects included in the PCI lists take place at the distribution network level. This trend is expected to continue in the next decade as DSOs would need to accommodate vast amount of RES capacity to be able to respond to the EU 2050 decarbonisation goals [46]. The increasing importance of smart grids and the achievement of the above objectives are reflected in the proposed Regulation revision which is expected to be adopted and implemented for the sixth PCI list in 2023. The new Regulation will include new criteria, new infrastructure categories with potential synergies/dependencies with electricity smart grids (e.g., with smart gas grids), an emphasis on projects focusing on increasing capacities for RES connections, sector coupling, etc. [42]

In this context, the assessment framework should be accordingly adapted, especially given the new policy goals, operational challenges, and the expected increase in the number of candidate PCIs and different type of projects, continuing the trend of recent years. This could also imply that a stricter selection will be necessary, while competing project proposals can also be expected, thus, increasing the need for more comparable project submissions. Furthermore, based on the first-hand experience we had, both in providing support to project promoters for the preparation of their proposals and in evaluating the projects' impact, we list below possible adjustments of the assessment framework that could facilitate and accelerate deployment of smart grids.

Considering the above:

- $\quad$ An updated framework should foresee common parameters for the social CBA and more impacts should be monetised to facilitate the projects' comparison. 
- $\quad$ The KPIs need to be updated to reflect the new Regulation, and provide detailed methods/equations for their calculation, especially where monetisation is feasible.

- The contributions of the candidate project to sustainability need to be highlighted and become a separate step in the assessment.

- An updated framework needs to facilitate the development of smart grid PCIs whose major investments occur at the distribution network level and therefore facilitate DSODSO cooperation, also in respect to the need to demonstrate a cross-border impact for projects that do include a physical interconnection.

- The synergies and dependencies with other PCIs should be clearly described, while combining different candidate projects under a single proposal ('clustering') should be encouraged and considered.

- An updated framework will need to explicitly consider the expected increased sector coupling(s) given the electrification of other end-use sectors (transport and heating) and factor in the potential of smart grids in unlocking the potential of those new end-users in providing flexibility to the energy system. However, it should be noted that calculating cross-sectoral impacts can be challenging.

- In a survey conducted on behalf of the EC, smart grid project promoters considered that the exclusion of low voltage infrastructures and the $20 \%$ RES generation requirement in the network covered by the project, hinders the deployment of smart grid projects in regions with a lower penetration of RES. Another challenge is that there are six specific criteria for smart grids while there are only three for other project categories (four for gas projects) [37].

\section{Conclusions}

Electricity smart grids are key infrastructures for the achievement of the EU's climate and energy policies. In this paper, we discuss our experience gained with the selection of PCIs in the thematic area of smart grids deployment, in the context of the TEN-E Regulation, and provide recommendations on how the assessment framework for projects selection could be aligned with the new TEN-E objective to support the European Green Deal. We start our discussion with a review of the requirements and basic components of an assessment methodology for energy infrastructure projects, in view of the Regulation and the existing literature. The Regulation has been supporting smart grid projects since 2013, and we provide an overview of the assessment methodology implemented for the selection of projects to be included in the PCI lists, given its goals and constraints. We also provide an overview of all the smart grid PCI since the first list in 2013 with the aim to closely look into the type of projects, the regional challenges of European network operators, and the added value of pursuing a joint project under the TEN-E framework. Finally, several high-level proposals were provided for the update of the assessment framework, given the EU's acceleration of its climate goals, the expected changes to the legislative framework (TEN-E Revision) and the new operational challenges that DSOs and TSOs need to address in the coming decades.

Author Contributions: Conceptualization, J.V. and T.E.; methodology, J.V.; resources, J.V. and T.E.; writing-original draft preparation, T.E.; writing-review and editing, J.V. and T.E.; supervision, T.E.; project administration, T.E.; funding acquisition, T.E. All authors have read and agreed to the published version of the manuscript.

Funding: This work was supported by the Joint Research Centre of the European Commission (WP 2022-2023).

Institutional Review Board Statement: Not applicable.

Informed Consent Statement: Not applicable.

Data Availability Statement: Not applicable.

Acknowledgments: The authors would like to thank Stamatios Chondrogiannis and Gianluca Flego. The usual disclaimer applies. 
Conflicts of Interest: The authors declare no conflict of interest.

\section{Abbreviations}

The following abbreviations are used in this manuscript:

$\begin{array}{ll}\text { ACER } & \text { Agency for the Cooperation of Energy Regulators } \\ \text { CBA } & \text { cost-benefit analysis } \\ \text { DSO } & \text { Distribution system operator } \\ \text { EC } & \text { European Commission } \\ \text { ENTSO-E } & \text { European Network of Transmission System Operators for Electricity } \\ \text { EU } & \text { European Union } \\ \text { KPI } & \text { Key performance indicator } \\ \text { NTC } & \text { Net transfer capacity } \\ \text { PCI } & \text { Project of Common Interest } \\ \text { RES } & \text { Renewable energy sources } \\ \text { TEN-E } & \text { Trans-European Networks for Energy } \\ \text { TSO } & \text { Transmission system operator } \\ \text { VOLL } & \text { Value of lost load }\end{array}$

\section{Appendix A}

The framework defines the following key performance indicators (KPIs) for evaluating each candidate project's contributions to the Regulation's specific criterion (source [8]):

- $\mathrm{KPI}_{1}$-reduction in greenhouse emissions

- $\mathrm{KPI}_{2}$-environmental impact of electricity grid infrastructure

- $\mathrm{KPI}_{3}$-installed capacity of distributed energy resources in distribution networks

- $\mathrm{KPI}_{4}$-allowable maximum injection of electricity without congestion risks in transmission networks

- $\mathrm{KPI}_{5}$ - energy not withdrawn from renewable sources due to congestion or security risks

- $\mathrm{KPI}_{6}$ - methods adopted to calculate charges and tariffs, as well as their structure, for generators, consumers and those that do both

- $\mathrm{KPI}_{7}$-operational flexibility provided for dynamic balancing of electricity in the network

- $\mathrm{KPI}_{8}$-ratio of reliably available generation capacity and peak demand

- $\mathrm{KPI}_{9}$ - share of electricity generated from renewable sources

- $\mathrm{KPI}_{10}$ - stability of the electricity system

- $\mathrm{KPI}_{11}$-duration and frequency of interruptions per customer, including climaterelated disruptions

- $\mathrm{KPI}_{12}$-voltage quality performance

- $\mathrm{KPI}_{13}$-level of losses in transmission and distribution networks

- $\mathrm{KPI}_{14}$-ratio between minimum and maximum electricity demand within a defined time period

- $\quad \mathrm{KPI}_{15}$ - demand side participation in electricity markets and in energy efficiency measures

- $\mathrm{KPI}_{16}$ - percentage utilisation of electricity network components

- $\mathrm{KPI}_{17}$-availability of network components and its impact on network performances

- $\mathrm{KPI}_{18}$ - actual availability of network capacity with respect to its standard value

- $\mathrm{KPI}_{19}$-ratio between interconnection capacity of a Member State and its electricity demand

- $\quad \mathrm{KPI}_{20}$ - exploitation of interconnection capacities

- $\mathrm{KPI}_{21}$-congestion rents across interconnections. 


\section{References}

1. A European Green Deal. Available online: https:/ / europa.eu/!Tr74bn (accessed on 15 January 2022).

2. European Commission. Regulation (EU) no 347/2013 of the European Parliament and of the Council of 17 April 2013 on guidelines for Trans-European Energy Infrastructure. 2013. Available online: http://data.europa.eu/eli/reg/2013/347/oj (accessed on 15 February 2022).

3. European Commission. Regulation (EU) no 1316/2013 of the European Parliament and of the Council of 11 December 2013 Establishing the Connecting Europe Facility. 2013. Available online: http:/ / data.europa.eu/eli/reg/2013/1316/oj (accessed on 15 February 2022).

4. Connecting Europe Facility. Available online: https:/ / europa.eu/!mXHBHf (accessed on 15 January 2022).

5. Key Cross Border Infrastructure Projects. Available online: https:/ / europa.eu/!pJvH83 (accessed on 15 January 2022).

6. SINCRO.GRID. Available online: https:/ / www.sincrogrid.eu/en (accessed on 15 January 2022).

7. Danube InGrid. Available online: https:/ / danubeingrid.eu/ (accessed on 15 January 2022).

8. Vasiljevska, J.; Gras, S. Assessment Framework for Projects of Common Interest in the Field of Smart Grids-2017 Update, EUR 28439; Publications Office of the European Union: Luxembourg, 2017. [CrossRef]

9. European Commission. Guide to Cost-Benefit Analysis of Investment Projects: Economic Appraisal Tool for Cohesion Policy 2014-2020; Publications Office: Luxembourg, 2015. [CrossRef]

10. Brent, R.J. Applied Cost-Benefit Analysis; Edward Elgar Publishing: Cheltenham, UK, 2006.

11. Drèze, J.; Stern, N. The theory of cost-benefit analysis. In Handbook of Public Economics; Elsevier: Amsterdam, The Nerthlands, 1987; pp. 909-989. [CrossRef]

12. Ergas, H.; Robson, A.R. The Social Losses from Inefficient Infrastructure Projects: Recent Australian Experience. 2009. Available online: http:/ / dx.doi.org/10.2139/ssrn.1465226 (accessed on 15 February 2022).

13. De Nooij, M. Social cost-benefit analysis of electricity interconnector investment: A critical appraisal. Energy Policy 2011, 39, 3096-3105. [CrossRef]

14. ENTSO-E. Guideline for Cost Benefit Analysis of Grid Development Projects. 2015. Available online: https://tyndp.entsoe.eu/cba (accessed on 15 February 2022).

15. Banez-Chicharro, F.; Olmos, L.; Ramos, A.; Latorre, J.M. Estimating the benefits of transmission expansion projects: An AumannShapley approach. Energy 2017, 118, 1044-1054. [CrossRef]

16. EU Third Energy Package. Available online: https:/ / europa.eu/!FyFd74 (accessed on 15 January 2022).

17. European Commission, Joint Research Centre; Giordano, V.; Onyeji, I.; Fulli, G.; Sanchez Jimenez, M.; Filiou, C. Guidelines for Cost Benefit Analysis of Smart Metering Deployment; EUR 25103; Publications Office of the European Union: Luxembourg, 2012. [CrossRef]

18. European Commission, Joint Research Centre; Giordano, V.; Onyeji, I.; Fulli, G.; Sanchez Jimenez, M.; Filiou, C. Guidelines for Conducting a Cost-Benefit Analysis of Smart Grid projects; EUR 25246; Publications Office of the European Union: Luxembourg, 2012. [CrossRef]

19. European Commission, Joint Research Centre; Giordano, V.; Vitiello, S.; Vasiljevska, J. Definition of an Assessment Framezork for Projects of Common Interest in the Field of Smart Grids under the EC "Proposal for a Regulation of the European Parliament and of the Council on Guidelines for Trans-European Energy Infrastructure"; EUR 25828; Publications Office of the European Union: Luxembourg, 2012. [CrossRef]

20. European Commission, Joint Research Centre; Vitiello, S.; Flego, G.; Setti, A.; Fulli, G.; Liotta, S.; Alessandroni, S.; Esposito, L.; Parisse, D. A Smart Grid for the City of Rome: A Cost Benefit Analysis; EUR 27158; Publications Office of the European Union: Luxembourg, 2015. [CrossRef]

21. Flego, G.; Vitiello, S.; Fulli, G.; Marretta, L.; Stromsather, J.; European Commission, Joint Research Centre. Cost-Benefit Analysis of Smart Grid Projects: Isernia: Costs and Benefits of Smart Grid Pilot Installations and Scalability Options; EUR 29222; Publications Office of the European Union: Luxembourg, 2018. [CrossRef]

22. ENTSO-E. Ten-Year Network Development Plans. Available online: https:/ /tyndp.entsoe.eu/ (accessed on 15 January 2022).

23. ACER. Methodology for Calculating the Value of Lost Load, the Cost of New Entry and the Reliability Standard. 2020. Available online: https: / / europa.eu/!tkHmpK (accessed on 15 February 2022).

24. Trinomics. Evaluation of the TEN-E Regulation and Assessing the Impacts of Alternative Policy Scenarios. 2018. Available online: https: / / data.europa.eu/doi/10.2833/736216 (accessed on 15 February 2022).

25. 2nd ENTSO-G. Methodology for Cost Benefit Analysis of Gas. Infrastructure Projects. 2019. Available online: https://www. entsog.eu/methodologies-and-modelling (accessed on 15 February 2022).

26. European Commission; Giordano, V.; Vitiello, S.; Filiou, C.; Gras, S.; Mrdeza, M. Evaluation of Smart Grid Projects within the Smart Grid Task Force Expert Group 4 (EG4): Application of the Assessment Framework for Energy Infrastructure Projects of Common Interest in the Field of Smart Grids; Publications Office: Luxembourg, 2013.

27. European Commission, Joint Research Centre; Vasiljevska, J.; Lucas, A. Evaluation of Candidate Projects of Common Interest in the Field of Smart Grids; Publications Office: Luxembourg, 2016. [CrossRef]

28. European Commission, Joint Research Centre; Gras, S.; Vasiljevska, J.; Flego, G. Evaluation of Smart Grid Projects for Inclusion in the Third Union-Wide List of Projects of Common Interest: Evaluation of Candidate Projects in the TEN-E priority Thematic Area of Smart Grids Deployment; Publications Office: Luxembourg, 2017. [CrossRef] 
29. European Commission, Joint Research Centre; Vasiljevska, J.; Flego, G. Identification of Projects of Common Interest in the Priority Thematic Area of Smart Grids Deployment: Evaluation of Candidate Projects under the EU Regulation 347/2013 on Trans-European Energy Infrastructure; Publications Office: Luxembourg, 2019. [CrossRef]

30. European Commission, Joint Research Centre; Vasiljevska, J.; Flego, G. Projects of Common Interest in the priority Thematic Area of Smart Grids Deployment: Evaluation of Candidate Projects under EU Regulation 347/2013 on Trans-European Energy Infrastructure; Publications Office: Luxembourg, 2021. [CrossRef]

31. European Parliament. Directive (EU) 2019/944 of the European Parliament and of the Council of 5 June 2019 on Common Rules for the Internal Market for Electricity and Amending Directive 2012/27/EU. 2019. Available online: http:/ / data.europa.eu/eli/ dir/2019/944/oj (accessed on 15 February 2022).

32. ACON. Available online: https://www.acon-smartgrids.cz/ (accessed on 15 January 2022).

33. CARMEN. Available online: https://delgaz.ro/smart-grid/informatii-generale/en (accessed on 15 January 2022).

34. Gabreta. Available online: https://www.gabreta-smartgrids.eu/ (accessed on 15 January 2022).

35. ACER. Consolidated Report on the Progress of Electricity and Gas Projects of Common Interest. 2019. Available online: https:/ / europa.eu/!Hn7UxM (accessed on 15 February 2022).

36. ACER. Consolidated Report on the Progress of Electricity and Gas Projects of Common Interest. 2021. Available online: https:/ / europa.eu/!GMXgGj (accessed on 15 February 2022).

37. European Commission; Akkermans, F.; Le Den, X.; Heidecke, L.; Jansen, L.; Juárez, V.; Kácsor, E.; Mezősi, A.; Nigohosyan, D.; Nguyen, N.; et al. Support to the Evaluation of Regulation (EU) No 347/2013 on Guidelines for Trans-European Energy Infrastructure: Final report, Publications Office. 2021. Available online: https:// data.europa.eu/doi/10.2833/154438 (accessed on 15 February 2022).

38. A Europe Fit for the Digital Age. Available online: https:/ / europa.eu/!fG74BH (accessed on 15 January 2022).

39. EU Strategy for Energy System Integration. COM/2020/299. 2020. Available online: https://europa.eu/!jGfhvV (accessed on 15 January 2022).

40. European Parliament Resolution of 15 January 2020 on the European Green Deal. Available online: https://europa.eu/!yPMPbx (accessed on 15 January 2022).

41. European Commission. 'Fit for 55': Delivering the EU's 2030 Climate Target on the Way to Climate Neutrality. Available online: https:/ / europa.eu/!PRxTxc (accessed on 15 January 2022).

42. European Commission. Revised Rules for Cross-Border Energy Infrastructure in Line with the European Green Deal. Available online: https: / / europa.eu/!Tt66gt (accessed on 15 January 2022).

43. European Commission. 2050 long-Term Strategy—A Clean Planet for all. Available online: https:/ / europa.eu/!48ddN9 (accessed on 15 January 2022).

44. ACER. Position on Incentivising Smart Investments to Improve the Efficient Use of Electricity Transmission Assets. 2021. Available online: https:/ / europa.eu/!NVcvxb (accessed on 15 January 2022).

45. IEA. Digitalization and Energy. Available online: https://webstore.iea.org/digitalization-and-energy (accessed on 15 January 2022).

46. EURELECTRIC. Connecting the Dots: Distribution Grid Investment to Power the Energy Transition. Available online: https: / / www.eurelectric.org/connecting-the-dots / (accessed on 14 December 2021). 